\title{
Urostomy Prolapse
}

National Cancer Institute

\section{Source}

National Cancer Institute. Urostomy Prolapse. NCI Thesaurus. Code C78571.

Displacement of the urostomy. 